\title{
Liberação de flúor do Vitremer em diferentes proporções pó/líquido, em compação com dois selantes de fóssulas e fissuras
}

\author{
Juliana Fraga Soares Bombonatti * \\ Maria Fidela de Lima Navarro* \\ Elisa Rueda Elias ${ }^{* * *}$ \\ Marilia Afonso Rabelo Buzalaf ${ }^{* * *}$ \\ José Roberto Pereira Lauris ${ }^{* * *+}$ \\ Alberto Carlos Botazzo Delbem ${ }^{* * * * *}$
}

\begin{abstract}
Resumo
A proposta deste estudo in vitro foi avaliar a liberação de flúor do cimento de ionômero de vidro Vitremer/3M em três diferentes proporções pó/líquido (1:1, 1/2:1 e 1/4:1), em comparação com dois selantes: FluroShield/Dentsply e Vitro-Seal Alpha/DFL. Oito espécimes foram submetidos a um modelo de ciclagem de $\mathrm{pH}$, sendo imersos alternadamente em soluções de desmineralização (6h) e remineralização (18h) e outros oito mantidos em água deionizada a $37^{\circ} \mathrm{C}$ sob agitação, trocada diariamente, por 15 dias. A concentração de F liberada nos períodos de 24 horas, 7 e 15 dias foi analisada através do eletrodo íon específico (Orion 9609), após tamponamento com TISAB II. Os resultados, em $\mu \mathrm{gF} /$ $\mathrm{cm}^{2}$ demonstraram que o Vitremer nas proporçóes 1/2:1 e $\mathrm{e}^{1 / 4}: 1$, tanto $\mathrm{em}_{2} \mathrm{O}$ como em des-/re-, apresentou liberação de F significativamente maior em relação aos demais grupos, conforme mostrado pela ANOVA e pelo teste de Tukey $(\mathrm{p}<0,05)$, não tendo havido diferença estatística significativa entre o Vitremer 1/2:1 $\mathrm{e}^{1 / 1 / 4: 1}$ nas soluções de des-/re-. Assim, a alteração na consistência do Vitremer, tornando-o mais fluido, parece ser uma alternativa favorável sob o aspecto de liberação de F.
\end{abstract}

Palavras-chave: Selantes. Liberação de flúor. Cimento de ionômero de vidro.

\section{INTRODUÇÃO}

Atualmente, tem-se procurado o estabelecimento de novos conceitos para o tratamento da doença cárie. Cada vez mais, a atenção dos profissionais da área odontológica se volta para o aperfeiçoamento de técnicas que visem à prevenção da instalação de lesões cariosas.
A superfície oclusal é a que apresenta maior susceptibilidade à cárie em razão de sua própria morfologia, que permite o aprisionamento de resíduos alimentares e colonização bacteriana. ${ }^{3}$ Assim, a prevenção ou diminuição da incidência de cáries oclusais tem sido uma preocupação constante na Odontologia.

* Prof ${ }^{a}$ de Dentística e Materiais Odontológicos. Universidade Paranaense - UNIPAR/Cascavel. Doutoranda em Dentística. FOB-USP/Bauru.

${ }^{* *}$ Prof $^{a}$ Titular do Departamento de Dentística, Endodontia e Materiais Dentários. FOB-USP/Bauru. Faculdade de Odontologia de Bauru - Universidade de São Paulo

Al. Dr. Octávio Pinheiro Brisolla, 9-75

17.012-901 - Bauru SP Brasil

Fone: (14) 235-8200; Fax: (14) 223-4679

E-mail:mflnavar@usp.br

${ }^{* * *}$ Bolsista de Iniciação Científica - FAPESP.

${ }^{* * * *}$ Prof $^{\underline{2}} \mathrm{Dr}^{\underline{\underline{a}}}$ do Departamento de Odontopediatria, Ortodontia e Saúde Coletiva. FOB-USP/Bauru.

***** Prof. Dr. do Departamento de Bioquímica FOB-USP/Bauru.

${ }^{* * * * * *}$ Prof. Dr. do Departamento de Odontopediatria. FOA-UNESP/Araçatuba. 
Existem vários métodos para se tentar controlar a cárie dentária. Dentre eles, o flúor tópico tem ocupado um papel de destaque; porém, sua maior atuação é sobre as superfícies lisas e, conseqüentemente, mesmo uma terapia intensiva com flúor não se sobrepõe a esta susceptibilidade da face oclusal. Este fato levou os pesquisadores a buscar, no selamento da região de fóssulas e fissuras, um método que fosse efetivo para o controle da cárie.

De acordo com Featherstone e colaboradores, ${ }^{10}$ Ten Cate, ${ }^{20}$ Ten Cate e Featherstone, ${ }^{21}$ sabese que a presença contínua de baixas concentrações de flúor pode inibir a desmineralização e favorecer a remineralização.

Assim, além da retenção, um outro aspecto interessante a ser observado nos materiais utilizados para selamento de fóssulas e fissuras é a liberação de flúor, que pode ser encontrada em alguns selantes resinosos, como constatado por Cooley e colaboradores, ${ }^{4}$ em 1990, e por Cury, Saad e Rodrigues Jr., ${ }^{8}$ em 1993, em cujos trabalhos o selante FluroShield demonstrou liberação de concentraçôes significativas de fluoretos.

Devido a esta característica de liberar flúor dos cimentos de ionômero de vidro, ${ }^{6,12}$ diversos estudos $^{11,14,17,18}$ demonstram a eficácia deste material como um método adicional, na tentativa de prevenir cáries na superfície oclusal.

Mais recentemente, os ionômeros foram modificados pela adição de componentes resinosos, o que conferiu maior resistência e retenção a esse material. E ainda, de acordo com McCabe, ${ }^{16}$ através de uma revisão de literatura sobre cimentos de ionômero de vidro modificados, a liberação de flúor desses materiais é considerada semelhante à observada nos cimentos de ionômero de vidro convencionais.

Um outro aspecto bastante interessante é a capacidade que esses materiais possuem de absorver flúor do meio para posterior liberação, estendendo o prazo de tempo no qual o flúor ficará disponível no meio bucal. ${ }^{6,12,22}$

Sabe-se que os cimentos de ionômero de vidro, se manipulados na proporção indicada pelo fabricante, apresentam uma alta viscosidade, difi- cultando sua penetração na região de cicatrículas e fissuras.

Assim, a ampla utilização desses materiais como selante tornou necessário o aperfeiçoamento da técnica para melhor aproveitamento do material.

Uma alternativa clínica tem sido a alteração da proporção pó/líquido, ${ }^{15}$ obtendo-se uma mistura com maior fluidez, buscando melhor penetração do material no interior das fissuras, ${ }^{19}$ porém sem a devida comprovação na literatura, para que se conhecessem quais as conseqüências desta alteração em relação à capacidade de liberação de flúor destes materiais diluídos.

Dessa maneira, a proposição do presente estudo foi avaliar a liberação de flúor em soluções de desmineralização/remineralização e em água deionizada, por um período de quinze dias, de um selante resinoso (FluroShield - Dentsply), um compômero para selante (Vitro-Seal Alpha - DFL) e um cimento de ionômero de vidro modificado por resina (Vitremer - 3M) manipulado em três grupos com diferentes proporções pó/líquido: proporção indicada pelo fabricante (1:1), proporção pó/líquido de $1 / 2: 1$ e de $1 / 4: 1$.

\section{MATERIAIS E MÉTODOS}

Foram confeccionados 16 corpos-de-prova para cada um dos cinco grupos experimentais, tendo sido distribuídos uniformemente em água deionizada e em sistema de ciclagem de $\mathrm{pH}$ (solução de des-/re- alternadamente). Foi utilizada uma matriz de náilon constituída por um orifício central de $11,0 \mathrm{~mm}$ de diâmetro e $1,5 \mathrm{~mm}$ de espessura com uma fenda para a colocação de um fio dental, possibilitando a suspensão do corpo-deprova para sua imersão.

A matriz foi preenchida à temperatura ambiente de aproximadamente $25^{\circ} \mathrm{C}$, sendo os materiais (QUADRO 1) manipulados, inseridos e fotoativados de acordo com as especificações dos respectivos fabricantes. Os selantes FluroShield e Vitro-Seal Alpha foram inseridos com o próprio bico dosador do recipiente, enquanto o 
Vitremer, nas diferentes proporçôes, foi inserido através de seringa Centrix.

A proporção pó/líquido do Vitremer nos diferentes grupos foi estabelecida por peso, em balança de precisão, conforme descrito a seguir:

$\begin{array}{ll}\text { Vitremer 1:1 } & 0,5 / 0,2 \mathrm{~g} \\ \text { Vitremer 1/2:1 } & 0,5 / 0,4 \mathrm{~g} \\ \text { Vitremer 1/4:1 } & 0,5 / 0,8 \mathrm{~g}\end{array}$

\begin{tabular}{|l|l|l|l|}
\hline Material & $\begin{array}{l}\text { Nome } \\
\text { comercial }\end{array}$ & Fabricante & Lote \\
\hline $\begin{array}{l}\text { Cimento de } \\
\text { ionômero de vidro }\end{array}$ & Vitremer & $\begin{array}{l}\text { 3M Dental } \\
\text { Products }\end{array}$ & 20010327 \\
$\begin{array}{l}\text { Selante resinoso } \\
\text { Compômero }\end{array}$ & $\begin{array}{l}\text { FluroShield } \\
\text { Vara selamento }\end{array}$ & Dentsply & 62501 \\
\hline
\end{tabular}

Quadro 1 - Materiais e respectivos fabricantes utilizados para a confecção dos corpos-de-prova

O preenchimento da matriz foi feito em excesso, sobre uma placa de vidro, e a mesma foi pressionada com outra placa de vidro, permanecendo nessa posição durante toda a polimerização. A fotoativação foi realizada dos dois lados da matriz através de um aparelho fotopolimerizador (VIP Variable Intensity Polymerizer/Bisco, com $600 \mathrm{~mW} / \mathrm{cm}^{2}$ ), durante 40 segundos para todos os materiais manipulados.

As amostras eram então removidas da matriz e suspensas pelo fio dental em tubos de ensaio plásticos com tampa, sendo que metade das amostras permanecia imersa em 2,0ml de água deionizada com trocas a cada 24 horas e a outra metade com $2,0 \mathrm{ml}$ de solução do sistema de ciclagem de $\mathrm{pH}$, permanecendo 6 horas na solução de desmineralização e 18 horas na solução de remineralização; assim, as trocas sucederam-se diariamente, durante um período de 15 dias.

O sistema de ciclagem de $\mathrm{pH}$ utilizado foi o desenvolvido por Featherstone e colaboradores, ${ }^{9}$ em 1986, e empregado por Carvalho e Cury, ${ }^{1,2}$ sendo composto por uma solução de desmineralização ( $\mathrm{Ca} 2,0 \mathrm{mM}, \mathrm{PO}_{4} 2,0 \mathrm{mM}$ e tampão acetato $75 \mathrm{mM}, \mathrm{pH} 4,3$, contendo $\mathrm{NaN}_{3}$ a $0,02 \%$ ) e uma solução de remineralização (Ca 1,5mM, $\mathrm{PO}_{4} 0,9 \mathrm{mM}, \mathrm{KCl} 150 \mathrm{mM}$ e tampão tris $20 \mathrm{mM}, \mathrm{pH}$ 7,0, contendo $\mathrm{NaN}_{3}$ a $0,02 \%$ ).

Os tubos exigiram um vedamento eficiente, a fim de evitar a evaporação das soluções. Para tanto, utilizou-se cera 7 no orifício feito na tampa para a passagem do fio dental.

Os tubos de ensaio permaneceram em banho-maria, numa temperatura de $37^{\circ} \mathrm{C}$, sob agitação em uma mesa agitadora Unitronic-or Selecta, com velocidade de agitação de $55 \mu / \mathrm{min}$, sendo a mesma interrompida somente nos períodos de troca das soluçôes. Depois do tempo de imersão, as amostras eram removidas das soluçôes, retirava-se o excesso de umidade com papel absorvente e colocava-se na solução subseqüente. Os tubos que já haviam passado pela mesa agitadora eram armazenados em câmara fria à temperatura de $4^{\circ} \mathrm{C}$, por um período máximo de 120 dias até a leitura.

A concentração de flúor liberada nas soluçôes, nos períodos de 24 horas, 7 e 15 dias, foi medida com um eletrodo $\mathrm{F}^{-}$sensível (Orion modelo 9609-BN). O eletrodo era calibrado previamente à leitura com uma série de soluções-padrão $(0,05$ a $12,8 \mu \mathrm{g} \mathrm{F} / \mathrm{ml}$ em TISAB II). Assim, os valores das leituras de F em milivoltagem nas soluções foram transformados em quantidade de $\mathrm{F}^{-}$liberada por área de material $\left(\mu \mathrm{gF} / \mathrm{cm}^{2}\right)$.

Para a análise do F- liberado, adicionou-se $0,5 \mathrm{ml} \mathrm{da}$ amostra a igual volume de TISAB II (tampão acetato $1,0 \mathrm{M}, \mathrm{pH} 5,0$ contendo $\mathrm{NaCl}$ 1,0 M e CDTA 0,4\%). Tanto os tubos da amostra como os frascos preparados com TISAB II eram agitados em um Agitador de Tubos - Modelo 251 (Fanem) previamente às leituras.

Algumas amostras precisaram ser diluídas em água deionizada ou em soluçôes de des- ou re-, para que pudessem ser comparadas com os resultados dos padróes.

Os valores encontrados nas soluções de desmineralização e remineralização foram somados para a obtenção da liberação de flúor em 24 horas, permitindo comparação com a liberação em água no mesmo período. 


\section{RESULTADOS}

As médias $\left(\mu \mathrm{gF} / \mathrm{cm}^{2}\right)$ e respectivos desviospadrão da liberação de flúor em água deionizada e em des-/re- dos cinco grupos experimentais nos períodos de 24 horas, 7 e 15 dias, encontram-se descritos na Tabela 1.

A análise de variância (ANOVA) a três critérios foi aplicada aos resultados, tendo, como fatores de variação, material, solução e tempo, demonstrando existir diferença estatisticamente significativa $(\mathrm{p}<0,01)$ para cada fator e também interação entre eles.

Assim, aplicou-se ANOVA separadamente nos períodos de 1, 7 e 15 dias, considerandose apenas dois fatores de variação: material e solução, tendo sido encontrada diferença estatisticamente significativa $(\mathrm{p}<0,001)$ para os fatores material, solução e interação nos três períodos analisados. Em seguida, foi aplicado o teste de Tukey $(\mathrm{p}<0,05)$ para comparações individuais entre os grupos, representado na Tabela 1.

A maior liberação de flúor ocorreu nas primeiras vinte e quatro horas, com diminuição gradual dessa liberação após 7 e 15 dias.

O teste de Tukey demonstrou que o Vitremer nas proporçôes de 1/2:1 e 1/4:1, tanto em $\mathrm{H}_{2} \mathrm{O}$ como em des-/re-, apresentou liberação de flúor significativamente maior em relação aos demais grupos, exceto no sétimo dia, quando os grupos Vitremer 1/2:1 em água e Vitremer 1:1 em des-/re- não apresentaram diferença estatística significativa.

Ocorreu maior liberação de flúor para o Vitremer nas proporçôes de $1 / 2: 1$ e $1 / 4: 1$ nas soluçôes de des-/re- nos três períodos avaliados, não tendo sido encontrada diferença significativa entre eles. O Vitremer 1/2:1 em des-/re- não demonstrou diferença significativa em relação ao Vitremer 1/4:1 em água. Os grupos VitroSeal Alpha e FluroShield apresentaram os menores valores de liberação de flúor, sem diferença estatística significativa entre eles.

Para todos os grupos experimentais, os valores numéricos indicaram maior liberação de flúor nas soluçôes de des-/re- quando comparados com a liberação em água, porém com diferença estatisticamente significativa apenas nos grupos do Vitremer nas proporções de 1/2:1 e $1 / 4: 1$.

\section{DISCUSSÃO}

O material odontológico que apresenta liberação de flúor tem sido avaliado, normalmente, em condiçôes que não simulam o meio ambiente bucal, a dinâmica de desenvolvimento da cárie e os conceitos atuais sobre o mecanismo de ação do flúor. ${ }^{1,2}$

Tabela 1- Médias $\left(\mu \mathrm{gF} / \mathrm{cm}^{2}\right)$ e respectivos desvios-padrão da liberação de flúor em água deionizadae em des-/redos 5 grupos experimentais nos períodos de 24 horas, 7 e 15 dias e representação do teste de Tukey

\begin{tabular}{|c|c|c|c|c|c|c|c|c|c|c|}
\hline \multicolumn{3}{|c|}{ Vitro-Seal Alpha } & \multicolumn{2}{|c|}{ FluroShield } & \multicolumn{2}{|c|}{ Vitremer 1:1 } & \multicolumn{2}{|c|}{ Vitremer 1:1 } & \multicolumn{2}{|c|}{ Vitremer 1/4:1 } \\
\hline & $\mathrm{D} / \mathrm{R}$ & $\mathrm{H}_{2} \mathrm{O}$ & $\mathrm{D} / \mathrm{R}$ & $\mathrm{H}_{2} \mathrm{O}$ & $\mathrm{D} / \mathrm{R}$ & $\mathrm{H}_{2} \mathrm{O}$ & $\mathrm{D} / \mathrm{R}$ & $\mathrm{H}_{2} \mathrm{O}$ & $\mathrm{D} / \mathrm{R}$ & $\mathrm{H}_{2} \mathrm{O}$ \\
\hline 1 & $\begin{array}{l}4,20 \mathrm{a} \\
(0,74)\end{array}$ & $\begin{array}{l}3,33 \mathrm{a} \\
(0,50)\end{array}$ & $\begin{array}{c}14,94 \mathrm{ab} \\
(6,36)\end{array}$ & $\begin{array}{c}13,17 \mathrm{ab} \\
(6,07)\end{array}$ & $\begin{array}{l}42,64 c \\
(16,25)\end{array}$ & $\begin{array}{c}34,70 \mathrm{bc} \\
(3,68)\end{array}$ & $\begin{array}{c}131,90 \text { ef } \\
(28,28)\end{array}$ & $\begin{array}{c}77,38 \mathrm{~d} \\
(8,36)\end{array}$ & $\begin{array}{c}148,75 \mathrm{f} \\
(29,84)\end{array}$ & $\begin{array}{c}122,49 \text { e } \\
(18,65)\end{array}$ \\
\hline 7 & $\begin{array}{c}0,26 \mathrm{ab} \\
(0,04)\end{array}$ & $\begin{array}{l}0,08 \mathrm{a} \\
(0,03)\end{array}$ & $\begin{array}{c}2,52 \mathrm{ab} \\
(0,68)\end{array}$ & $\begin{array}{c}1,06 \mathrm{ab} \\
(0,33)\end{array}$ & $\begin{array}{c}7,70 \mathrm{~cd} \\
(3,67)\end{array}$ & $\begin{array}{c}5,04 \mathrm{bc} \\
(0,88)\end{array}$ & $\begin{array}{c}20,41 \mathrm{ef} \\
(4,54)\end{array}$ & $\begin{array}{c}11,14 \mathrm{~d} \\
(1,44)\end{array}$ & $\begin{array}{c}24,40 \mathrm{f} \\
(6,09)\end{array}$ & $\begin{array}{c}17,07 \mathrm{e} \\
(3,49)\end{array}$ \\
\hline 15 & $\begin{array}{l}0,10 \mathrm{a} \\
(0,04)\end{array}$ & $\begin{array}{l}0,03 \mathrm{a} \\
(0,01)\end{array}$ & $\begin{array}{c}1,00 \mathrm{ab} \\
(0,25)\end{array}$ & $\begin{array}{l}0,46 \mathrm{a} \\
(0,14)\end{array}$ & $\begin{array}{l}4,02 c \\
(1,81)\end{array}$ & $\begin{array}{c}3,22 \mathrm{bc} \\
(0,57)\end{array}$ & $\begin{array}{c}11,61 \text { ef } \\
(2,21)\end{array}$ & $\begin{array}{l}7,03 \mathrm{~d} \\
(0,90)\end{array}$ & $\begin{array}{l}14,26 \mathrm{f} \\
(3,89)\end{array}$ & $\begin{array}{c}9,75 \text { de } \\
(1,98)\end{array}$ \\
\hline
\end{tabular}

Nota: Letras diferentes demonstram diferença estatisticamente significativa $(p<0,05)$. 
De acordo com Carvalho e Cury, ${ }^{2}$ é importante que a análise quantitativa de flúor liberado seja realizada utilizando-se corpos-de-prova imersos em soluções que reproduzam o ambiente bucal, ou seja, em que haja períodos de desmineralização e remineralização pela ciclagem de $\mathrm{pH}$. Este método, idealizado por Featherstone e colaboradores, ${ }^{9}$ consegue representar uma situação intrabucal de alta cariogenicidade, momento em que mais se necessita da ação do flúor.

Segundo Cury, Saad e Rodrigues Jr., ${ }^{8}$ a água deionizada, normalmente utilizada para a avaliação da liberação de flúor, não simula a composição inorgânica, as interações da superfície, a força iônica, o pH do meio e o grau de saturação, sendo que esses fatores são importantes para a velocidade com que os íons flúor são liberados.

Os resultados obtidos parecem estar de acordo com esta afirmativa, uma vez que demonstraram maior liberação de flúor nas soluçôes de des/re- do que em água deionizada, apesar de ter sido estatisticamente significativa apenas nos grupos do Vitremer nas proporçôes de 1/2:1 e 1/4:1.

Independentemente do meio e dos grupos experimentais, houve liberação de maior quantidade de fluoreto nas primeiras vinte e quatro horas, com diminuição gradual dessa liberação nos períodos seguintes.

Este comportamento foi bastante nítido no cimento de ionômero de vidro, cujo endurecimento ocorre em duas fases, a inicial e a tardia, sendo esta última mais lenta. A fase tardia dura em média vinte e quatro horas, determinando as propriedades mecânicas finais do material, período no qual ocorre maior liberação de flúor.

O bom desempenho dos cimentos ionoméricos em relação à liberação de flúor, quando comparado a outros produtos, foi também confirmado por vários autores. ${ }^{1,2,5,6,12}$

Apesar de não ter demonstrado diferença estatística significativa, os valores de liberação de flúor do FluroShield foram numericamente superiores em comparação com o compômero Vitro-Seal Alpha. Esse selante resinoso foi testado também em outros estudos como os de Cooley e colaboradores, ${ }^{4}$ em 1990 , e de Cury,
Saad e Rodrigues Jr., ${ }^{8}$ em 1993, observando-se bom comportamento frente à liberação de flúor.

Os grupos em que se utilizou o Vitremer nas proporçôes pó/líquido de 1/2:1 e $1 / 4: 1$, quando imersos alternadamente nas soluçôes de des-/re-, foram os que liberaram maior quantidade de flúor, demonstrando diferença estatística significativa em relação aos demais grupos.

A alteração da proporção pó/líquido do Vitremer, tornando a mistura final mais fluida, vem sendo utilizada clinicamente ${ }^{15}$ e, de acordo com Fracasso, ${ }^{13}$ permite uma penetração do selante no interior da fissura semelhante à encontrada para os selantes resinosos.

Esta modificação na consistência do cimento de ionômero de vidro pode ter influenciado na liberação de flúor, graças à presença de maior quantidade de líquido na reação química responsável pelo endurecimento do material.

A liberação de flúor ocorre sob a forma de fluoreto de sódio, que é decomposto durante a reação de endurecimento; assim, estando presente maior quantidade de líquido, poderá haver uma maior extração de íons da superfície do pó.

De acordo com os resultados encontrados, a alteração da proporção pó/líquido do cimento de ionômero de vidro, tornando-o mais fluido, parece ser uma alternativa interessante para a utilização deste material como selante de fóssulas e fissuras. O mesmo demonstrou comportamento superior aos produtos desenvolvidos especificamente para esta indicação, como, no caso, os selantes FluroShield e Vitro-Seal Alpha.

Esta liberação de flúor foi ainda superior quando da simulação de uma condição de alto risco à cárie, fator importante na indicação deste material em pacientes de alto risco.

\section{CONCLUSÕES}

De acordo com a proposição, a metodologia empregada e os resultados obtidos, pôde-se concluir que:

a) Independentemente do meio e dos grupos experimentais, houve liberação de maior quantidade de flúor nas primeiras vinte e quatro horas. 
b) A liberação de flúor foi significativamente maior nas soluções de des-/re- do que em água deionizada para os grupos em que o Vitremer teve a proporção pó/líquido alterada. c) A alteração na consistência do cimento de ionômero de vidro Vitremer, tornando-o mais fluido, favoreceu a liberação de flúor.

\title{
Fluoride release of Vitremer in different powder/liquid ratio compared to two pit and fissure sealants
}

\begin{abstract}
The purpose of this in vitro study was to evaluate the fluoride $(F)$ release of Vitremer/3M in 3 groups with different powderlliquid ratios (VT 1:1, VT 1/2:1 e VT 1/4:1) in comparison with two sealants FluroShield/ Dentsply (FS) and Vitro-Seal Alpha/DFL (VS). Eight specimens were submitted to a pH-cycling system. They were immersed alternatively in de (6h) and re-mineralization solutions ( $1 \mathrm{~h})$, while 8 specimens were immersed in agitated non ionized water at $37^{\circ} \mathrm{C}$, exchanged daily during 15 days. The $F$ concentration released in 24 hour periods, in 7 and 15 days, was measured by using the ion specific electrode (Orion 9609), after buffering with TISAB II. Vitremer in the powder/liquid ratio of $1 / 2: 1$ and $1 / 4: 1$ both in water and in delre-mineralization solutions had a higher F release when compared to the other groups, as revealed by the results of the ANOVA and the Tukey's test $(p<0,05)$. There were no significant differences between VT $1 / 2$ and VT $1 / 4$ in de and remineralization solutions. Thus, the alteration of the Vitremer consistence, as far as the fluidity is concerned, suggests that it may be a favorable alternative concerning the F release.
\end{abstract}

Keywords: Sealants. Fluoride release. Glass ionomer cement.

\section{REFERÊNCIAS}

1 CARVALHO, A. S.; CURY, J. A. Liberação de flúor de materiais restauradores. R. Odontol. Univ. São Paulo, São Paulo, v.12, n.4, p.367-373, out./dez. 1998.

2 CARVALHO, A. S.; CURY, J. A. Fluoride realease from some dental materials in different solutions. Oper. Dent., Seattle, v.24, p.14-19, 1999.

3 CARVALHO, J. C.; EKSTRAND, K. R.; THYSTRUP, A. A. Dental plaque and caries on occlusal surfaces of first permanent molars in relation to stage of eruption. J. Dent. Res., Alexandria, VA, v.68, p.773-779, 1989.

4 COOLEY, R. L. et al. Evaluation of fluoride-containing sealant by SEM, microleakage, and fluoride release. Pediatr. Dent., Chicago, v.12, n.1, p.38-42, Feb. 1990.

5 CRANFIELD, M.; KUHN, A. T.; WINTER,G. B. Factors relating to the rate of fluoride-ion release from glass-ionomer cement. J. Dent., Kidlington, v.10, n.4, p.333-341, 1982.

6 CREANOR, S. L. Fluoride uptake and release characteristics of glass ionomer cements. Caries Res., Basel, v.28, n.5, p.322-328, 1994.
7 CRISP, S.; LEWIS, B.; WILSON, A. D. Glass ionomer cements: chemistry of erosion. J. Dent. Res., Alexandria, VA, v.55, n.6, p.1032-1041, Nov./Dec. 1976.

8 CURY, J. A.; SAAD, C. R. J.; RODRIGUES JR., L.A. Liberação de flúor do selante. RGO, Porto Alegre, v.41, n.5, p.273-275, set./out. 1993.

9 FEATHERSTONE, J. D. B. et al. Enhancement of remineralization in vitro and in vivo. In: $\mathrm{LEACH}, \mathrm{S}$. A. Factors relating to demineralization and remineralization of the teeth. Oxford: IRL Press, 1986. p.23-24.

10 FEATHERSTONE, J. D. B. et al. Dependence of in vitro demineralization of apatite and remineralization of dental enamel on fluoride concentration. J. Dent. Res., Alexandria, VA, v.69, p.620-625, Feb. 1990. Número especial.

11 FORSS, H.; SEPPA, L. Prevention of enamel demineralization adjacent to glass ionomer filling 
materials. Scand. J. Dent. Res., Copenhagen, v.98, n.2, p.173-178, Apr. 1990.

12 FORSTEN, L. Fluoride release from a glass ionomer cement. Scand. J. Dent. Res., Copenhagen, v.85, p.503-504, Nov. 1977.

13 FRACASSO, M. L. C. Avaliação da infiltração marginal e da profundidade da penetraçáo apresentada por alguns cimentos de ionômero de vidro e um selante resinoso aplicados em fossas e fissuras oclusais: estudo in vitro. 2001. Dissertação (Mestrado) - Faculdade de Odontologia de Bauru, Universidade de São Paulo, São Paulo, 2001.

14 KARLZÉN-REUTERVING, G.; VAN DIJKEN, J. W. V. A three-year follow-up of glass ionomer cement and resin fissure sealants. ASDC J. Dent. Child., Chicago, v.62, n.2, p.108-110, Mar./Apr. 1995.

15 MACHADO, M. A. A. M. et al. Evaluation of the enamel pretreatments on the retention of a glass ionomer cement used as a sealant. J. Dent. Res., Alexandria, VA, v.79, n.5, p.1038, May 2000.

16 McCABE, J. F. Resin modified glass-ionomer. Biomaterials, Oxford, v.19, n.6, p.521-525, Mar. 1998.
17 MCLEAN, J. W.; WILSON, A. D. Fissure sealing and filling with an adhesive glass ionomer cement. Br. Dent. J., London, v.136, n.2, p.269-276, Apr. 1974.

18 MEJÁRE, I.; MJOR, I. A. Glass ionomer and resin based fissure sealants: a clinical study. Scand. J. Dent. Res., Copenhagen, v.98, n.4, p.345-350, Aug. 1990.

19 RIOS, D. Avaliação do desgaste e rugosidade superficial de materiais utilizados para selante, submetidos à escovação com dois diferentes dentifrícios. 2000. Dissertação (Mestrado) - Faculdade de Odontologia de Bauru, Universidade de São Paulo, São Paulo, 2000.

20 TEN CATE, J. M. In vitro studies on the effects of fluoride on de- and remineralization. J. Dent. Res., Alexandria, VA, v.69, p.614-619, Feb. 1990. Número especial.

21 TEN CATE, J. M.; FEATHERSTONE, J. D. Mechanistic aspects of the interactions between fluoride and dental enamel. Crit. Rev. Oral Biol. Med., Alexandria, VA, v.2, p.283-296, 1991.

22 TENUTA, L. M. A. et al. Effect of fluoridated gel and solution on fluoride uptake by glass ionomer cement. J. Dent. Res., Alexandria, VA, v.76, p.318, May 1997.

\section{Agradecimentos}

Nossos agradecimentos a Thelma Lopes da Silva, do Departamento de Bioquímica da FOB-USP, e à Prof Dr $^{\mathrm{a}}$ Salete Moura Bonifácio da Silva, do Departamento de Odontopediatria da FOB-USP. 